\title{
Assessment of Nurse's Perception Towards Their Profession and Factors Affecting It in Debre Berhan Town Governmental Health Institution, Debre Berhan, Ethiopia
}

\author{
Mikiyas Amare Getu ${ }^{1,}$, Addis Adera Gebru ${ }^{1}$, Bogale Eshete Semaw ${ }^{2}$ \\ ${ }^{1}$ Department of Nursing, Faculty of Health Sciences, Woldia University, Woldia, Ethiopia \\ ${ }^{2}$ Department of Nursing, Faculty of Health Sciences, Debre Berhan University, Debre Berhan, Ethiopia
}

Email address:

amaremikiyas@gmail.com (A. G. Mikiyas), addisaderagebru@gmail.com (G. A. Adera), eshetebogale@gmail.com (E. S. Bogale)

\section{To cite this article:}

Mikiyas Amare Getu, Addis Adera Gebru, Bogale Eshete Semaw. Assessment of Nurse's Perception Towards Their Profession and Factors Affecting It in Debre Berhan Town Governmental Health Institution, Debre Berhan, Ethiopia. American Journal of Nursing Science. Vol. 4, No. 6, 2015, pp. 297-304. doi: 10.11648/j.ajns.20150406.11

\begin{abstract}
Background: Nursing is a health care profession, which is focused on the care of individuals, families, and communities; so that they can attain, maintain, or recover optimum health. Nursing care is given for individuals of all age groups and different cultural backgrounds who are healthy and ill in a holistic manner based on the individual's physical, emotional, psychological, intellectual, social, and spiritual needs. Objective: To assess Nurses' Perception and towards Nursing profession and factors affecting it in Debre Birhan town governmental health institutions, Debre Berhan Ethiopia. Methods: Institution based quantitative cross sectional study design was used to assess nurse's perception and related factors among professional nurses. Convenience sampling method was used to select 105 intended study participants from Debre Berhan Referral Hospital and Debre Berhan town governmental health centers. Data collection was carried out using structured questionnaire. The collected data was entered using SPSS version 20.00 for further analysis. Odds ratio was calculated for related factors with $95 \%$ confidence interval (CI). A p-value $<0.05$ was considered to be statistically significant. Results: Out of 105 sample respondents 103 agreed to participate with the response rate of $98.1 \%$. More than half of nurses 54(52.4\%) were females and 49(47.6\%) were males. More than half of nurses 54(52.4\%) had good perception towards nursing. A significant Association was seen between monthly income level and perception of nursing $(\mathrm{P}<0.05)$. In addition monthly income and perception of important aspects of nursing had shown an association. Conclusion: Majority of nurses who participated in this study had good perception towards nursing. More than half of participants want to migrate to other countries for good career opportunity. Majority of nurses had an intention to leave their profession with the main cause of low salary. Occupational factors (salary) were identified as a leading factor which affects perception.
\end{abstract}

Keywords: Nurse's, Perception, Profession, Debre Birhan, Governmental Health Institution

\section{Introduction}

The historical and philosophical perspective of nursing started with Ms. Florence Nightingale the lady with a lamp who was a well-educated woman from an affluent class family became a nurse and improved the profession drastically in nineteenth century that people gradually began to accept nursing as a respectable profession in the society. At that time, nursing was seen as employment that needed neither study nor intelligence. Since Florence Nightingale's pioneering work, only five generations of nurses have set their footprints in history. In that short time, nursing has grown enormously in knowledge, skill, prestige, and value. Nursing needs to be recognized as a member of the scientific discipline that can make valuable contributions to health [1]. Perception of nursing may vary depending on age, educational level, social and professional experience and occupational and social factors [2]. The impact of low perception for nursing by professional nurses is not only limited to low job satisfaction but it also lead to the intention of leaving the profession. It is escalating the nursing shortage throughout the world [3]. Perception of nursing can be influenced by different factors that can lead nurses to have low job satisfaction, to leave their profession, and to have nursing shortage which ultimately affect health care delivery system and tendency of skilled 
professional nurses to be reluctant to provide bedside service. So to decrease the effect of low perception and maintaining the quality of health care it is high time to carry out scientific inquiry on perception of nurses on nursing profession and its related factors [4].This study will provide information about Nurses perception towards nursing profession and factors affecting it. There is knowledge gap in which nursing profession is predominantly recognized as female profession and limited to bedside care and drug administration instead of highly skilled and well educated nursing professional with important role to play in health care [5]. Most nursing students have negative attitude towards nursing profession in India. Nursing profession is not attractive for meritorious as well as other high school students; they do not see it as a good carrier option. Additionally, the media often portrays nurses as sex objects that are subservient to the doctors. Yet on the positive side, nursing has also been perceived as a caring and nurturing profession that requires a great deal of physical and emotional strength, patience, and knowledge [6]. Nurses comprise a majority of health care professionals but they are largely invisible and they have been silent about what they do and how they do it. The profession is considered to have limited role in decision making Hospital policy (has often limited nursing actions), Role confusion, Lack of professional confidence, Fear, Insecurity, and Sense of inferiority. This loss of professional pride and self-esteem can also lead to a more serious professional problem [5]. Researchers have revealed a number of negative societal perceptions of nursing related to gender stereotyping, subordination to doctors, low academic standards, limited career opportunities and poor pay and conditions, and importantly how these perceptions may affect levels of recruitment into nursing [7]. A serious nursing shortage is creating a crisis in the nation's health care system and poor quality of care. Many experienced nurses are leaving the field and young people are not selecting nursing as a potential career [4. Nursing shortage refers to a situation where the demand for registered nurses (RN) is greater than the supply. [8].Africa as a whole falls below the minimum standard, with 185 health workers for every 100000 people [9]. In contrast in Ethiopia health worker population ratio among all nurses without including midwifes, is 3870 people for each nurse according to 2008/09 G.C of health and health related indicators of federal democratic republic of Ethiopia [10]. This indicates that Ethiopia is facing shortage of nurses. Poor perception of nursing could have an impact on the coordinated work of health providers, to have low job satisfaction, to leave their profession and to have nursing shortage which results in poor quality of health care delivery. So we are interested to conduct this research to decrease the effect of low perception maintaining quality of health care. Several research studies reported that most of the nursing graduates are reluctant to join bed side nursing which is badly required by the health care industry and those who joined it has not right attitude towards the profession hence compromising quality nursing care which is essential in this era of quality assurance and patient bill of rights. [11].Therefore, the main aim of this study was to assess Nurses' Perception towards
Nursing profession and factors affecting it in Debre Berhan town governmental health institutions, Debre Berhan, Ethiopia.

\section{Methods and Materials}

\subsection{Study Area and Period}

The study was conducted in Debre Berhan town, North Shoa zone Amhara region which is about 130 kilometres north east Addis Ababa. Based on the 2012 national census conducted by the Central Statistical Agencyof Ethiopia (CSA), this town has a total population of 87,408 . The town has a total area of $14.71 \mathrm{~km}^{2}$ with an average elevation 2840 meters above sea level (12). Debre Birhan has 9 Kebele and 5 rural kebele. In the town, There is one governmental referral hospital, one private hospital, two health centre and 17 private clinics. The study was conducted from January2013 to June 2013G.C.

\subsection{Study Design}

Institution based quantitative cross sectional study design was used.

\subsection{Source Population}

All Nurses who are working in Debre Birhan town governmental health institution.

\subsection{Study Population}

All nurses working in Debre Birhan town governmental health centers and Debre Birhan Referral Hospital during study period.

\subsection{Eligibility Criteria}

\subsubsection{Inclusive Criteria}

- Nurses working in Debre Birhan town governmental health institution and available at the time of data collection.

\subsubsection{Exclusive Criteria}

- Those nurses who are not available at the time of data collection.

- Those nurses who provide free service.

\subsection{Sample Size Determination and Sampling Procedures}

\subsubsection{Sample Size}

The sample size was determined by using a formula for estimating a single population proportion. Since there is no study done on this topic, the sample size for this cross sectional study was calculated by assuming prevalence to be $50 \%$.

The sample size of the study was based on having $95 \%$ confidence interval and tolerable margin of error is $5 \%$.

$$
n=\frac{\left(Z_{\frac{a}{2}}\right)^{2} p(1-p)}{d^{2}}
$$


Where

$\mathrm{n}=$ estimated sample size

$\mathrm{Z}=$ standard normal distribution $(\mathrm{Z}=1.96)$ with confidence interval of $95 \%$ and $\alpha=0.05$

$\mathrm{P}=$ prevalence (population proportion)

$\mathrm{d}=$ marginal error

$$
n=\frac{1.96^{2} \times 0.5(1-0.5)}{0.05^{2}}=\frac{3.84 \times 0.25}{0.0025}=384
$$

Since the study population is less than 10,000 finite population correction formula is applied:

Where $\mathrm{n} i=$ calculated sample size

$\mathrm{n} f=$ exact sample size

$\mathrm{N}=$ sample population

$$
n f=\frac{384 \times 128}{384+128}
$$

$\mathrm{n} f=96$

Adding 10\% non response rate $9.6=105$

\subsubsection{Sampling Procedure}

Convenience sampling method was used to select intended study subjects from Debrebirhan town governmental health institution.

According to the data obtained from Debre Birhan town governmental hospital and health centres there are 112,9,7 nurses in DBRH, Debrebirhan town kebele 04 heath center, DebreBirhan town Kebele 07 health center respectively. There are a total of 128 nurses in the town.

For the hospitals to proportionate the number of study subject using $\mathrm{nf} / \mathrm{N} \times \mathrm{n}$

DBRH $(105 \times 112) / 128=92$

Kebele 04 health center $(105 \times 9) / 128=7$

Kebele 07 health center $(105 \times 7) / 128=6$

\subsection{Data Collection Tools}

The data collection was carried out using structured questionnaire which was adopted from the study conducted in UK and Spain, posted on international journal of Nursing Studies [17]. The questionnaire which was prepared in English was translated to Amharic for ease of use. The questionnaire contains 9 socio - demographic characteristic; Age, sex, ethnic group, marital status, educational status, religion, monthly income, work experience and health institutions they are working in. Thirty five Nursing dimension inventory (NDI) stem questions used to assess nurses perception towards nursing profession which was designed as likert scale which ranges from not important to very important And last part of the questionnaire contains one question to assess factors that affect perception.

\subsection{Data Collection Methods}

Data was collected by self-administered method. Questionnaires were distributed for selected nurses in the hospital and health centers.

The data was collected by five $4^{\text {th }}$ year nursing students from Debre Birhan University. Before the actual data collection, data collectors have had half day training about the aim of the study and the content of the instrument. Therefore, the data collectors became familiar about each question. It was used a mechanism of minimizing bias during the process of data collection.

From the group members one of the students served us supervisor and facilitator to our work by checking the completed questionnaire and by correcting mistakes which are done by other group members. The principal investigators also randomly checked at least $5 \%$ of the supervisors work each day for completeness and relevancies and gave feed back when it was necessary.

\subsection{Variables}

\subsubsection{Dependent Variable}

Perception of nurses towards nursing profession

\subsubsection{Independent Variables}

- Socio demographic data

- (Age, sex, ethnic group, marital status, educational status, Religion, monthly income, work experience, and working hospital).

- Individual/personal nurse factors: ( commitment, personal values and ethics; reflective practice; interests and fears, gender, resilience, adaptability and self confidence; and family work/life balance).

- Organizational Professional/occupational factors:(scope of practice, level of autonomy and control over practice, and interdisciplinary relationships) and

- External professional/occupational factors:(policies and regulations at the provincial/territorial, national and international level)

\subsection{Operational Definition}

External Professional/Occupational Factors include policies and regulations at the provincial/territorial, national and international level which influence health and social policy and role socializations within and across disciplines and domains.

Individual /personal factors include the personal attributes and/or acquired skills and knowledge of the nurse. Included among these factors are commitment, personal values and ethics; reflective practice; interests and fears, gender, resilience, adaptability and self confidence; and family work/life balance.

Organizational Professional/Occupational Factors are characteristic of the nature and role of the profession/occupation. Included among these factors are the scope of practice, level of autonomy and control over practice, and interdisciplinary relationships.

Nurse - is a professional who is registered by ministry of health and working in accredited hospitals and health centres.

Nurse professionals - Nurses who are working in Debre Birhan hospitals and health centers

Perception - is an idea, belief, or an image you have as a result of how you see or understand nursing. 
Good perception towards nursing profession is $\geq$ mean value

Poor perception towards nursing profession is $<$ mean value

\subsection{Data Processing and Analysis}

Data was checked in the field to ensure that all the information is properly collected and recorded. Before and during data processing the information was checked for completeness. SPSS 20.00 version statistical soft ware was employed for data entry and analysis. The analysis included checking errors and describing the collected data by numerical summary measures tables, charts and measures of association. Multiple attributes for outcome variables checked for its association by binary logistic regression. Odds ratios have been calculated for related factors with $95 \%$ confidence interval $(\mathrm{CI})$. A p-value $<0.05$ was considered to be statistically significant.

\subsection{Data Quality Assurance}

The quality of data was assured by using a standard NDI questionnaire which was employed in UK and Spain to assess nurses' perception. Pre-test of the questionnaire was conducted at Ayu hospital and other private clinics on 5\% of estimated sample size to check clarity, consistency and to make necessary amendment on the questionnaire two weeks before actual data collection. To keep the consistency of the questionnaires, it was prepared first in English and then it was translated to Amharic and finally back to English. The check list was prepared in English and closer supervision was undertaken during data collection by our assigned supervisor then the supervisor and investigators checks the consistency and completeness of the check list and completed questionnaires daily. The collected information was rechecked for its competence and consistency before entering the data into the computer.

Similarly, training was offered to the supervisors to avoid hypothetical bias and ensure proper categorization and coding of questionnaires. Furthermore, supervisors and the principal investigator checked the collected data thoroughly on daily basis for its completeness. The data collected every day was packed. To obtain the data with quality first tell the objective or purpose of the study to our respondents.

\subsection{Ethical Considerations}

The study was conducted after getting ethical clearance from Debre Berhan University, college of Medicine and Health Science, Department of Nursing. Support Letter was obtained from Debre Birhan University to respective health institutions for their cooperation during the conducting of the study. At individual level after explaining the purpose of the study, informed consent was obtained from all participants prior to their participation in this study. Participants were informed that privacy and confidentiality was maintained. Information obtained from study participants to ensure confidentiality was kept and their names are not written rather code given for each respondent for anonymity. At the end of the study, the result was communicated to students, staff and respective institutions the study units culture, language, beliefs and value was respected. The study subjects was informed that the study process will have no intended harm to them and confidentiality will be kept. Any study participants who are not willing to be included in the study was not forced to be included in the study.

\subsection{Dissemination of the Result}

After the data is analyzed, based on the findings obtained, conclusions and recommendations were made. Then the result of the study was submitted to Department of Nursing (DBU), Debre Birhan Referral Hospital, Debre Birhan Health bureau, the Federal Ministry of Health, Ethiopia Nurses Association. More over the findings of the study would be published and disseminated through different journals and scientific publications and policy makers which are involved in health sector can use the findings of this study.

Table 1. Socio-demographic characteristic of nurses at Debere Birhan governmental health institution, Debre Birhan, Ethiopia, 2013.

\begin{tabular}{|c|c|c|c|}
\hline \multicolumn{2}{|c|}{ Socio demographic Characteristics } & \multirow{2}{*}{$\begin{array}{l}\text { Frequency } \\
66\end{array}$} & \multirow{2}{*}{$\begin{array}{l}\text { Percentage } \\
64.1\end{array}$} \\
\hline \multirow{5}{*}{ Age } & $20-29$ & & \\
\hline & $30-39$ & 29 & 28.2 \\
\hline & $40-49$ & 5 & 4.9 \\
\hline & $>50$ & 3 & 2.9 \\
\hline & Total & 103 & 100 \\
\hline \multirow{3}{*}{ Sex } & Female & 54 & 52.4 \\
\hline & Male & 49 & 47.6 \\
\hline & Total & 103 & 100 \\
\hline \multirow{5}{*}{ Marital status } & Unmarried & 49 & 47.6 \\
\hline & Married & 47 & 45.6 \\
\hline & Divorced & 6 & 5.8 \\
\hline & Widowed & 1 & 1.0 \\
\hline & Total & 103 & 100 \\
\hline \multirow{4}{*}{ Educational status } & Diploma & 73 & 70.9 \\
\hline & Bachelor science degree & 28 & 26.7 \\
\hline & Masters science degree & 2 & 1.9 \\
\hline & Total & 103 & 100 \\
\hline \multirow{5}{*}{ Monthly income } & 1427-1644 birr & 44 & 42.7 \\
\hline & $1645-2249$ birr & 36 & 35.0 \\
\hline & 2250-2989 birr & 20 & 19.4 \\
\hline & 2989 and above & 3 & 2.9 \\
\hline & Total & 103 & 100 \\
\hline \multirow{5}{*}{ Religion } & Orthodox Christianity & 81 & 78.6 \\
\hline & Protestant & 14 & 13.6 \\
\hline & Muslim & 7 & 6.8 \\
\hline & Catholic & 1 & 1.0 \\
\hline & Total & 103 & 100 \\
\hline \multirow{6}{*}{ Work experience } & $0-5$ years & 74 & 71.8 \\
\hline & $6-10$ years & 16 & 15.5 \\
\hline & $11-15$ years & 8 & 7.8 \\
\hline & $16-20$ years & 4 & 3.9 \\
\hline & $>21$ & 1 & 1.0 \\
\hline & Total & 103 & 100 \\
\hline \multirow{4}{*}{$\begin{array}{l}\text { Health institution } \\
\text { you are working in }\end{array}$} & $\begin{array}{l}\text { Debrebirhan referral } \\
\text { hospital }\end{array}$ & 92 & 89.3 \\
\hline & Kebele 04 health center & 5 & 4.9 \\
\hline & Kebele 07 health center & 6 & 5.8 \\
\hline & Total & 103 & 100 \\
\hline
\end{tabular}




\section{Results}

\section{Sociodemographic characteristics}

Of 105 nurses involved in the study 103 agreed to respond and made a total response rate of $98.1 \%$. The majority of the respondents $66 \%$ were in the age group of 20-29 years, followed by in the age group of 30-39 years. The remaining was in the age group of 40-49 years and 50 years and above (table 1).

Table 2. Perception of nurses towards nursing profession in governmental health institution of Debreberhan town, DebreBerhan, Ethiopia 2013.

\begin{tabular}{lll}
\hline Perception of nursing profession & Frequency & Percentage \\
\hline Good perception & 54 & 52.4 \\
Poor perception & 49 & 47.6 \\
Total & 103 & 100 \\
\hline
\end{tabular}

Possible scores on the NDI 35 stem questions could range from 35 to 175 . In this study, the scores ranged from 62 to 166. The mean score was 129.9 (SD 42.9). More than half of nurses $54(52.4 \%)$ of nurses participate in our study have good perception (show table 2).

Association of variables and perception of nurses towards nursing profession

On Bi-variate analysis done to look relationship between variables with the perception of nursing. Those who have an income 2250-2989 ETB(Ethiopian Birr) have 5.78 times more likely to have good perception than who have monthly income $1427-1644 \mathrm{ETB}$ (COR=5.78,95\% CI:1.66-20.2) pvalue of 0.009 . Those who present themselves to patient and families are 4.65 times more likely to have good perception than who are not present themselves to the patient and families. $(\mathrm{COR}=4.65, \mathrm{CI}: 1.66-13.0) \mathrm{P}: 0.003)$. Nurses who are interested in current dressing style have 2.63 times more likely to have good perception than who are not interested on current dressing style.(COR $=2.63,1.17-5.90), \mathrm{P}: 0.019)$. Nurses who have skilful performance at their jobs have 0.22 times slightly higher likelihood to have poor perception than nurse who have no skilful performance at their jobs $(\mathrm{COR}=0.22,0.06-0.86)$ P: 0.030$)$. (show on table 3$)$

Table 3. Association between variables \& perception of Nurses towards nursing profession among nurses in Debre Berhan town governmental health institution, Debreberhan, Ethiopia, 2005.

\begin{tabular}{|c|c|c|c|c|c|c|}
\hline \multirow{2}{*}{ Variables } & & \multicolumn{2}{|c|}{ Perception } & \multirow{2}{*}{$p$ - value } & \multirow{2}{*}{$\operatorname{COR}(95 \% \mathrm{CI})$} & \multirow[t]{2}{*}{$\operatorname{AOR}(95 \% C I)$} \\
\hline & & Poor & Good & & & \\
\hline \multirow{4}{*}{ Age } & $20-29$ & 32 & 34 & 0.885 & & \\
\hline & $30-39$ & 13 & 16 & & $1.16(0.48-2.78)$ & $0.54(0.46-6.27)$ \\
\hline & $40-49$ & 3 & 2 & & $0.63(0.98-4.00)$ & $0.62(0.50-7.67)$ \\
\hline & $>50$ & 1 & 2 & & $1.88(0.10-21.7)$ & $0.34(0.02-6.70)$ \\
\hline \multirow{2}{*}{ Sex } & Female & 25 & 29 & & & \\
\hline & Male & 24 & 25 & 0.785 & $0.90(0.41-1.94)$ & $0.90(0.41-1.97)$ \\
\hline \multirow{4}{*}{ Marital status } & Unmarried & 23 & 26 & & & \\
\hline & Married & 22 & 25 & 0.990 & $1.00(0.45-2.24)$ & $0.96(0.38-2.41)$ \\
\hline & Divorced & 4 & 2 & & $0.44(0.07-2.64)$ & $0.36(0.43-3.11)$ \\
\hline & Widowed & 0 & 1 & & & \\
\hline \multirow{3}{*}{ Educational status } & Diploma & 36 & 37 & 0.963 & & \\
\hline & Bacheoler science degree & 13 & 15 & & $1.12(0.47-2,69)$ & $0.92(0.35-2.42)$ \\
\hline & Masters science degree & 0 & 2 & & & \\
\hline \multirow{5}{*}{ Work experience } & $0-5$ & 36 & 38 & 0.735 & & \\
\hline & $6-10$ & 9 & 7 & & $0.74(0.25-2.19)$ & $0.99(0.29-3.32)$ \\
\hline & $11-15$ & 2 & 6 & & $2.84(0.54-15.0)$ & $3.40(0.57-20.3)$ \\
\hline & $16-20$ & 2 & 2 & & $0.94(1.27-7.09)$ & $0.62(0.46-8.47)$ \\
\hline & $>21$ & 0 & 1 & & & \\
\hline \multirow{3}{*}{ Heath institution you are working in } & Debre Berhan Referral hospital & 45 & 47 & 0.721 & & \\
\hline & Kebele 04 health center & 2 & 3 & & $1.43(0.22-9.00)$ & \\
\hline & Kebeleo7 health center & 2 & 4 & & $1.91(0.33-10.9)$ & \\
\hline \multirow{4}{*}{ Monthly income } & 1427-1644 birr & 26 & 18 & & & \\
\hline & $1645-2249$ birr & 18 & 18 & 0.009 & $1.44(0.60-3.51)$ & $0.37(0.31-4.50)$ \\
\hline & 2250-2989 birr & 4 & 16 & & $5.78(1.66-20.2)^{*}$ & $0.51(0.04-6.16)$ \\
\hline & 2989 and above & 1 & 2 & & $2.89(0.24-34.3)$ & $1.98(0.14-28.3)$ \\
\hline \multirow{2}{*}{$\begin{array}{l}\text { Present them selves to the patient } \\
\text { and families }\end{array}$} & Yes & 31 & 48 & 0.003 & $4.65(1.66-13)^{*}$ & $2.99(0.96-9.32)$ \\
\hline & No & 18 & 6 & & & \\
\hline \multirow{2}{*}{ Current dressing style } & Interested & 15 & 29 & 0.019 & $2.63(1.17-5.90)^{*}$ & $3.54(1.38-9.09) *$ \\
\hline & Not interested & 34 & 25 & & & \\
\hline \multirow{2}{*}{ Skilful performance at your jobs } & Yes & 46 & 42 & 0.030 & $0.02(0.06-0.86)^{*}$ & $0.11(0.23-0.51)^{*}$ \\
\hline & No & 3 & 12 & & & \\
\hline
\end{tabular}

\section{Discussion}

From a total of 35 NDI stem questions five questions for assessing perception towards important aspects of nursing and three questions for assessing perception towards unimportant aspects of nursing profession were selected. In a cross sectional study conducted in UK and Spain majority half of respondents have good perception towards nursing profession [13]. In congruent with the above study (54)52.4\% of nurses have good perception towards nursing profession. And $49(47.6 \%)$ have poor perception towards nursing profession. When we compare it with the 
perception of student nurses about the nursing profession it was found to be parallel which is good perception towards nursing profession [14].This is because the second year students had the highest level of positive perception of the profession which was followed by the first and third years.

In addition it was identified that there was a significant association between perception and monthly income level. Importantly, the more the nurses had better monthly income the better they had perception on important aspects of nursing. This is to say that as the nurses increase in their monthly income level their perception towards the important aspect of nursing was also increased. In a study conducted in Malaysia to assess upper secondary male students' perception of nursing as a career choice, Good salary, stability and low stress were the primary factors that influence them to join nursing profession. In these study families, friends, and teachers are the primary motivators to join the profession. This is because in this study area there is work burden of nurses and low salary which cannot be motivators to join the profession and in our study area families, teachers and friends are considered to be influential during care choice of students in addition to this poor media coverage of the profession and inadequate information about the profession leads families, friends and teachers to be primary motivators. According to the study which has been done in America on public versus registered nurses perception of nursing carer have had an intention to leave their profession because of workload, burnout and quality of care at the workplace have often been reported as important predictors of nurses' intention to leave their job[15]. But on the contrary the finding of this study showed that among total number professional nurses who participated in this study, 55(53.4\%) had an intention to leave or quit their profession and only $48(46.6 \%)$ had no intention to leave their profession. The main cause to have an intention to leave their profession was low salary which accounts $37(35.9 \%)$, and the second leading cause was work burden and administration issue which accounts $14(13.6 \%)$.This is majority of study participants are diploma holders there scale of salary is low. According to study in Punjab Future nurses' perception towards profession Majority of the students were attracted to migrate in foreign country in hope to get good professional opportunities and better quality of life [3]. Similarly in this study $87(84.5 \%)$ want to migrate to other countries for good carer opportunity. The study explored the need of strong leadership, lobbying for the autonomy of the profession, improving salary structure of the nurses. The study conducted in united states indicated that nurses thought Items: How they present themselves to patients and families, how they dress, how skilled they appear to be at their jobs, misinformation from TV and other media, whether we introduce ourselves as nurses, how they appear to get along with co-workers, how they act around the nursing station, and so on and, whether the patients and families feel that we care accounts $75-98 \%$ to be an important to the image of nursing and, Forty-five percent thought that how easily the patients and families can read staff name tags had a great effect on image had a great effect on image. Though the responses were varied for all 10 items, $8 \%$ indicated that dress was most important and $3 \%$ responded that changing nurses' attitudes was most important. In line with the previous study more than half of the participants are performing these important activities to the image of nursing which indicate their perception. There is also a significant association is present between get along with coworkers, being a member of nursing association, active participation at nurses meeting, having staff name tags that can be easily readable to the patients and families with perception of important aspects of nursing. The study was done in America about the public versus registered nurses perception. The study revealed $20 \%$ of RNs viewed nursing caring or compassion. While $20 \%$ of $\mathrm{RNs}$ considered nurses as caring. While $6 \%$ of the RNs considered RNs highly knowledgeable, qualified and skilled. $23 \%$ of $\mathrm{RNs}$ considered themselves as professionals. Only $4 \%$ of RNs perceived RNs as smart or highly educated compared to $7 \%$ of the public. similarly in this study of the total nurses present on the study $74(71.8 \%)$ perceived nursing profession as Caring and compassion, 64(62.1\%) Highly qualified, knowledgeable and skilful professionals $67(65.0 \%)$ An opportunity to serve humanity, $14(13.6 \%)$ an opportunity for personal growth, 15(14.6\%) a way to get due recognition and $12(11.7 \%)$ to earn blessings. In this study, study participants did not perceive nursing as a female profession. Similarly, Law \& Arthur [16] concluded that males have equally positive attitudes towards nursing. Also, Mkhize \& Nzimande [17, 18, 19] found that there was an increased interest among males to pursue nursing. According to study in Ontario about professionalism in nursing In this survey assessment of factors which affect perception towards nursing Occupational, Individual, extra occupational factors scored $50 \%, 20 \%$ and $19 \%$ of nurses respectively. The finding of this study in line with the previous. Under factors that affect good perception towards nursing, under occupational factors salary 74(71.8), under individual factors;54(52.4\%) skill and knowledge of nurse and under external occupational factors policies and regulations at the provincial/territorial, national and international level 35 $(34.0 \%)$ are affecting perception towards nursing Profession. According to study conducted in Tikur anbessa specialized hospital, Individual (knowledge and skill) and organizational (lack of training, workload, insufficient time and supportive managers) factors are the predominant factors that hinders implementation of Evidence based practice which can improve Nurses to have good perception towards their profession[20]. From a total score of $35 \mathrm{NDI}$ stem questions, 16654 nurses $(52.4 \%)$ had scored more than the mean score of 129.9 This showed that a sound perception towards nursing profession was held by above half of the nurses who participated in this study. 


\section{Conclusion and Recommendation}

\subsection{Conclusion}

From this study more than half of the study participants were found to have good perception towards nursing profession. Majority of nurses had an intention to leave their profession with the main cause of low salary. The relative and/or combined effects of demographic variables like sex, religion income, work experience, and education on the perception of professional nursing by nurses were examined; however, only monthly income had an association with perception of nursing. The study concluded that the perception of nursing profession among nurse professional majority of study participants perceived that nursing is a profession as caring and compassion, to serve humanity, and highly knowledgeable and skilful professionals are engaged in the profession.

Under factors which affect good perception towards nursing, skill and knowledge of nurse in individual factor and salary in occupational factors was found to be the leading factor. Nurse researchers recommended to carried out further research on perception of nurses towards their profession and to focus on the challenges of the contemporary nursing in Ethiopia in comparison to the status of the international nursing.

\subsection{Strength and Limitation}

The strength of the article is using standardized NDI stem question for analyzing perception.

The limitation of the study is participant groups were all selected on the basis of convenience; therefore, the extent to which the results may be generalized is limited.

\section{Authors Contributions}

MAG has made substantial contributions to beginning and design, collection of data, analysis and interpretation of data and in drafting the manuscripts and correcting the comments given by the advisors. BES involved in revising the research paper and the manuscript critically for important intellectual context and approval of the final version to be published and participated in its description. He participated in the design of the study participated in its design and coordination. AAG involved in revising the paper and the manuscript critically for the sake of intellectual context and approval of the final version to be published and participated in its design and coordination. In addition to this, they had great contribution in reviewing the manuscript English and Topography and helped to draft the manuscript.

\section{Acknowledgement}

We are thankful to all department technical staffs for their excellence technical support. We are grateful to all the participants for their cooperation and Debre Birhan University for financial support.

\section{References}

[1] Mundinger, marry. (1998)."nursing carer opportunities" in the pfizer guide: nursing carer opportunities. New York: NY: Pfizer, Inc.

[2] A. S. Hornbey, 2000, The Advanced learner's Dictionary of Current English, 6th edition, Oxford University press, p 864.

[3] Lewis M, Urmston J. Flogging the dead horse: the myth of nursing empowerment? Journal of Nursing Management. 2000; 8: 209-13. [PubMed].

[4] Wynd C., Current Factors Contributing to Professionalism in Nursing, 2003, Accessed on january 25, 2013, www.elsevier.com/locate/ijnurstu.

[5] Jamie White. The image of nursing: what it is and how it needs to change, Jones \& Bartlett Learning 86-106.

[6] Degazon CE, Shaw HK. Urban high school students' perceptions of nursing as a career choice. J Natl Black Nurses Assoc 2007; Jul; 18(1):8-13.

[7] Brodie D., Andrewa G., Andrews J., et al, perception of nursing, International Journal of Studies, February 26, 2004, Accessed on October 5, 2010,www.elsevier.com/locate/ijnurstu.

[8] Wikipedia, Nursing shortage, 2009, accessedon, January 25, 2013, http://en.wikipedia.org/wiki/Nursing_shortage.

[9] Solidarity research institute, Nursing shortage in south Africa, 2009, accessed on January 25, 2013, www.miningweekly.com/attachment.php.

[10] Federal Democratic Republic of Ethiopia Ministory of health, Health and health related indictors, Berhanenaselam publishing press, 2000/01(E.C), p 24, 2001.

[11] Lisa M. pugsley. Poster presentation: nurses attitude towards their profession. waters edge ballroom, Hilton Waikoloa village, jul: 2005.

[12] Wikipidia, Debrebirhan, 2012, accessedonmarch2, 2013, http://en.wikipedia.org/wiki/Debre_Berhan.

[13] Watson R., Deary I., Hoogbruin A., et. al. Perception of nursing, International Journal of Nursing Studies, June 24, 2002, Accessed on January 25, 2013, www.elsevier.com/locate/ijnurstu.

[14] Prudence Portia et'al, Psychosocial factors influencing the perception and choice of nursing as a profession: A study at Korle- $\mathrm{Bu}$ nurses' training college, Science publishing group, 2012, http://www.sciencepublishinggroup.com/j/pbs

[15] Donelan K., Desroches C., Dutwin D., public perception of nursing careers, 2008, accessed on October 18, 2010, http://www.medscape.com/viewarticle.

[16] Foskett, N. H. \& Hemsley-Brown, J. V. (1997). Career Perceptions and Decision-Making Retrieved September 23, 2008, from http:// www. hartgallery. org. uk/ journalsite/ capdemsum. DOC.

[17] Mkhize, S. \& Nzimande, S. (2007). Career Choices in Relation to Nursing: A Cross-Sectional Descriptive Study Investigating the Career Choices of School Leavers in Relation to Nursing, and What Influences These Choices. Durban: Health Systems Trust. Retrieved September 23, 2008, from Http// www.hst.org.za/uploads/files/nursingcareer.pdf. 
[18] Romem, P. \& Anson, O. (2005). Israeli men in nursing: social and personal motive, Journal of Nursing Management, 13(2), 173-178.

[19] Hephzibah alexander 2010 upper secondary male students perception of nursin $\mathrm{g}$ as a career choice, international journal for the advancement of science \&arts, vol. 1, no. 1, 2010 accessed on January 2013 www.ucsi.edu.
[20] G. Hadgu et'al, Assessment of Nurses' Perceptions and Barriers on Evidence Based Practice in Tikur Anbessa Specialized Hospital Addis Ababa Ethiopia, American journal of nursing science: Science publishing group: 2013. 